Original Scientific Article

\title{
FREE-ROAMING DOGS CONTROL ACTIVITIES IN ONE ITALIAN PROVINCE (2000-2013): IS THE IMPLEMENTED APPROACH EFFECTIVE?
}

\author{
Shanis Barnard ${ }^{1}$, Matteo Chincarini ${ }^{1}$, Lucio Di Tommaso ${ }^{2}$, \\ Fabrizio Di Giulio ${ }^{2}$, Stefano Messori ${ }^{1}$, Nicola Ferri ${ }^{1}$ \\ ${ }^{I}$ Istituto Zooprofilattico Sperimentale dell'Abruzzo e del Molise 'G. Caporale', \\ Campo Boario, 64100 Teramo, Italy \\ ${ }^{2}$ Servizio Sanità Animale Dipartimento di Prevenzione della ASL di Pescara, \\ Via Paolini 4765100 Pescara, Italy
}

Received 7 February 2015; Received in revised form 26 March 2015; Accepted 31 March 2015

\begin{abstract}
In Italy, standards for the management of free-roaming dogs (FRDs) are defined by regional norms, generating a high variability of approaches around the country. Despite efforts carried out by the competent authorities, FRDs are still a reality impacting upon animal health and welfare and public costs. A similar scenario can be found in many other Mediterranean and Balkan counties. Here we present 14 years of data (2000-2013) retrieved from the admission dog registry of a public shelter (PS) responsible for the collection of stray dogs from one Italian province. The aim of this retrospective study was to describe the local FRD population, identifying its source and to evaluate the effectiveness of the actions implemented by the local authorities. In the investigated period, 7,475 dogs were admitted to the PS. Despite the intense sterilisation plan (mean 381.7 sterilisations per year), the overall number of dogs entering PS did not decrease consistently across the years. Results highlighted a lack of responsibility of owners by failing to sterilise and identify their dogs and allowing intact animals to roam free, therefore producing uncontrolled and unwanted litters. The current dog population management strategy, based on both sheltering and capture-neuter-release programmes, is insufficient to tackle the straying phenomenon. Educational and sterilisation programmes should be an integral part of a successfully implemented FRD control plan. Our results provide further insight on free-roaming dog population dynamics and control systems, and may have important implications for many other local contexts across Europe trying to overcome the straying phenomenon.
\end{abstract}

Key words: dog, free-roaming, prevention, public health, shelter, welfare

\section{INTRODUCTION}

Free roaming dogs (FRDs) can represent an ecological, medical and social hazard in several ways to property, wildlife and farm animals (1). They can be reservoir of diseases transmissible to humans (zoonosis), attack people and other animals, cause accidents and can be responsible for nuisances and fouling $(2,3)$. Targeted actions addressing the issue are implemented by intergovernmental

Corresponding author: Dr. Shanis Barnard, $\mathrm{PhD}$

E-mail address: shanis.barnard@gmail.com

Present address: Istituto Zooprofilattico Sperimentale

dell'Abruzzo e del Molise 'G. Caporale',

Campo Boario, 64100 Teramo, Italy

Phone: $+39(0) 861332632$

Copyright: (C) 2015 Barnard S. This is an open-access article published under the terms of the Creative Commons Attribution License which permits unrestricted use, distribution, and reproduction in any medium, provided the original author and source are credited.

Competing Interests: The authors have declared that no competing interests exist.

Available Online First: 15 April 2015

http://dx.doi.org/10.14432/j.macvetrev.2015.04.041 organisations (e.g. OIE, FAO), as well as by the European Commission and the national competent authorities (4). Despite these efforts, FRDs still raise many animal welfare and public health issues and have an impact on public costs in many countries, especially in the Mediterranean and Balkan areas (5-7). At the first OIE regional Seminar on stray dog population management for the Balkan countries for example, $60 \%$ of the represented countries reported experiencing increasing trends in national stray dog populations in the past three years and all but two reported rabies in wildlife and domestic animals (8). The OIE offers detailed and complete guidelines on how to control stray dog populations (9). However, in most countries the legislation regulating dog population management and surveillance is promulgated at national or even local level, offering a scattered and un-harmonised framework. Although the drivers are very similar, authorities provide different implementation strategies. These are established on the basis of socio-economic, 
cultural and political components, but an effective and univocal formula for eradicating the problem has not been found (4-6).

The Italian national framework law 281/1991 on companion animals and stray dog prevention promotes dog identification and registration, birth control actions and protects stray and abandoned animals. This law forbids the euthanasia of stray animals unless they are seriously ill, incurable or proven dangerous (10). However, this national framework law does not provide standards for the managing and keeping of stray dogs, which are defined by the Regions. This has generated a high variability of approaches around the country, as can be also found in other European countries (6). The Abruzzi Region in central Italy for example, allows trap-neuter-release (TNR) programmes on the territory, whereas other Regions do not. At the municipality level, the Local Veterinary Health Unit (LVHU) is responsible for the capture and management of FRDs. All captured animals must be hosted in the local public shelter (PS) for health screening. Facilities such as PS can function as epidemiological observatories, systematically collecting valuable information on the structure, size and characteristics of the local FRD population.

Data gathered over a period of 14 years $(2000$ - 2013) from the admission registry of dogs at the PS of Pescara was retrieved. Pescara province (over 300 thousand inhabitants) is located in Central Italy in the Abruzzi Region, and was used as case study to understand local dog population dynamics and to investigate if it was possible, through a retrospective analysis, to identify causes and risk factors associated with the FRDs phenomenon and to identify ameliorative solutions. Although the eradication of the straying phenomenon might be an ambitious objective, a deeper insight into the population dynamics and the identification of gaps in the actions in place can help similar local contexts to implement more targeted and effective actions, thus improving overall public health and animal welfare.

\section{MATERIAL AND METHODS}

\section{Background information}

The LVHU managing the PS included in this study is responsible for the control and management of FRDs covering 46 municipalities of the Pescara province (including Pescara municipality). According to the Italian National Institute of Statistics (ISTAT www.istat.it, 2011), the territory of action of this $\operatorname{LVHU}\left(1,224 \mathrm{~km}^{2}\right)$ is divided in three areas: coastal/inland plain, hills and mountains. 150
The PS provides temporary housing for animals while they are checked and treated, if necessary, before deciding their destination. Dogs are caught from the streets after reports from police officers, animals' rights associations or citizens. According to the National Law 281/1991 (10), dogs in Italy have to be identified and registered. Owned dogs found roaming without a microchip are identified (with a transponder) by the shelter veterinarians before returning them, and a fine is applied to the owner following law prescriptions. Stray and abandoned animals are identified and registered, neutered and usually entrusted to rescue shelters for adoption. The regional law of Abruzzi also allows TNR programmes. Dogs under this programme are identified and registered as "community dogs" and are under the responsibility of the mayor of the municipality where the dog is released. These dogs are reintroduced to the territory under specific conditions i.e. the dog is sterilised, harmless and accepted by the community. Biting dogs which are reported for aggression, are kept under clinical (for rabies control) and behavioural observation for 10 days. They are kept either at the owner's house or if the dog is unknown, at the PS. If the dog is diagnosed as being dangerous, it has to be kept in the shelter or euthanized according to the national framework recommendations, otherwise it can be adopted or returned to its territory.

\section{Data collection}

All dogs entering the PS are registered in an electronic database, compiled by the two public veterinarians managing the facility. For this study, we retrieved the data recorded from January 2000 to December 2013. For each dog, information about sex, size, breed, age (estimate), place of capture, electronic identification, neutering/spaying status, general health status, stay time (days) and destination, were logged in. Since the shelter policy slightly changed during the investigated period, some data were not recorded across all years. When this was the case, missing data have been pointed out in the results section.

\section{Statistical analysis}

A descriptive screening of the data was carried out to investigate the variation in the variables across time or between groups of dogs entering the PS. Associations between variables were evaluated by applying the Chi-squared test and variations in time were analysed using linear regression models. Spearman correlation test was used to compare the number of caught dogs per municipality and the human population. Kruskal-Wallis test was applied to compare the dog/inhabitant ration in 
Free-roaming dogs control activities in one Italian province

the different type of territory (plain, mountain, and hill). Wilcoxon test was used to compare the age of sterilised versus non-sterilised animals entering the PS. Alpha value was set for $=0.05$. All analyses were carried out using $\mathrm{R}^{\circledR}$ version 2.15.3 software package for Windows 7 .

\section{RESULTS}

Sex, size and breed

The total number of dogs included in the study was 7,475 and on average, the number of dogs
The dog population was represented by large $(15 \%>26 \mathrm{~kg})$, medium (46\% 16-25 kg) and small $(39 \%<15 \mathrm{~kg})(11)$ size dogs (total $n=7,423)$.

Stay time in PS was on average 11 days (median=9 days) with the minimum being 1 day and the maximum being 195 days. After the first clinical check, dogs were either returned to their owner or sent to an adoption centre. Long stays were associated with dogs that needed surgery or special care due to severe injuries or sickness.

The majority $(77 \%)$ of captured dogs were mongrels (i.e. not ascribable to any breed, $n=5,643$ ). On average $403 \pm 68.3 \mathrm{sd}$ (median $=413.5$ ) mongrels

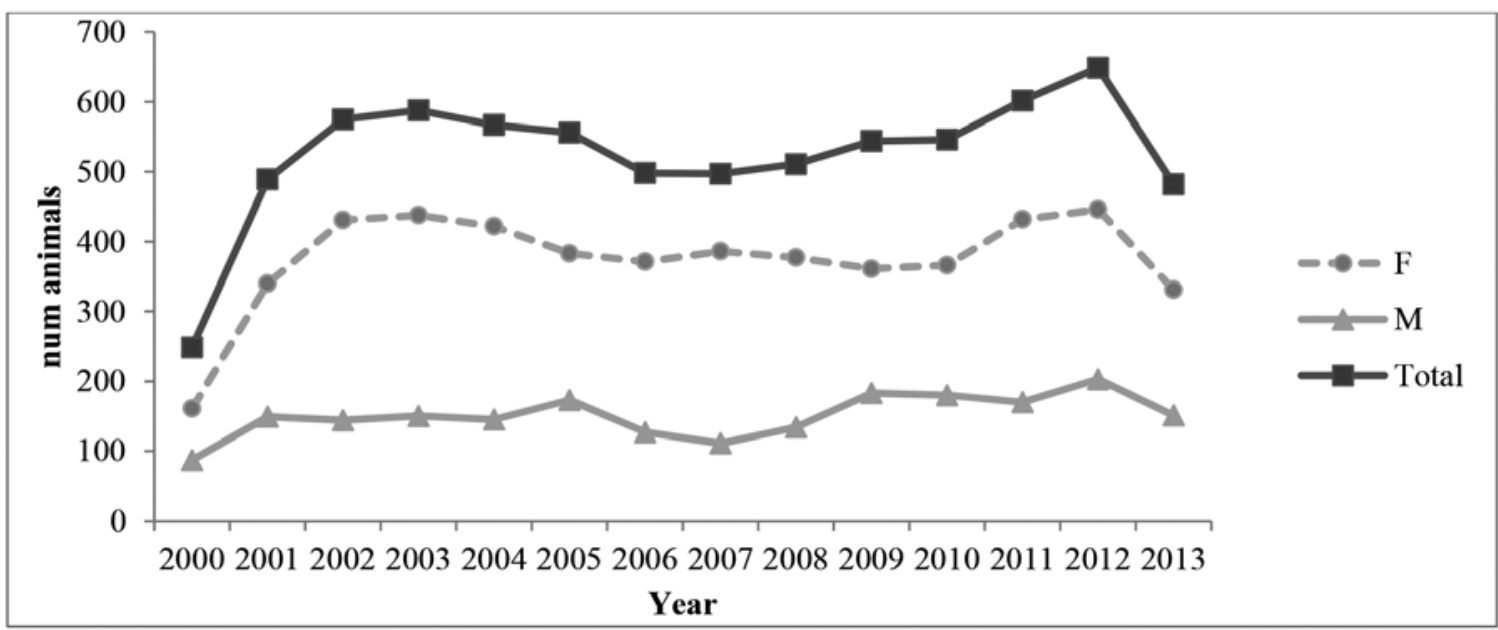

Figure 1. Number of shelter entries - Males (M), females (F) and total number of dogs entering the PS yearly between 2000 and 2013

entering the shelter annually was 530.1. In 54 cases, sex was not reported in the PS registry. Of the remaining 7,421 dogs, a higher proportion of female dogs $(71 \%)$ entered the PS compared to male dogs (29\%) (Fig. 1). entered each year in similar proportion. A further $12 \%(n=883)$ were cross-breeds with a morphology clearly associated to a breed (mean $\pm \mathrm{sd}=62.1 \pm 30.1$, median=61.5). Finally, $12 \%(n=865)$ were pure breed dogs $(\operatorname{mean} \pm \mathrm{sd}=61.4 \pm 13.5$, median=61.5) (see Table 1 for breeds details).

Table 1. Six most represented pure breeds and cross breeds in the sample entering the PS (proportions are calculated within each category)

\begin{tabular}{lll|llc}
\hline Pure breed $(\mathbf{n}=\mathbf{8 8 3})$ & $\mathbf{n}$ & $\mathbf{\%}+$ & Cross-breed $(\mathbf{n}=\mathbf{8 6 5})$ & $\mathbf{n}$ & $\mathbf{\%}$ \\
\hline German Shepherd & 209 & $24.5 \%$ & Abruzzi Sheepdog cross & 245 & $27.9 \%$ \\
Abruzzi Sheepdog & 162 & $18.9 \%$ & German Shepherd cross & 186 & $21.2 \%$ \\
Hound & 83 & $9.7 \%$ & Hound cross & 70 & $8.0 \%$ \\
Pit Bull & 82 & $9.6 \%$ & Siberian Husky cross & 44 & $5.0 \%$ \\
Rottweiler & 75 & $8.8 \%$ & Setter cross & 42 & $4.8 \%$ \\
Setter & 66 & $7.7 \%$ & Spitz cross & 30 & $3.4 \%$ \\
\hline
\end{tabular}




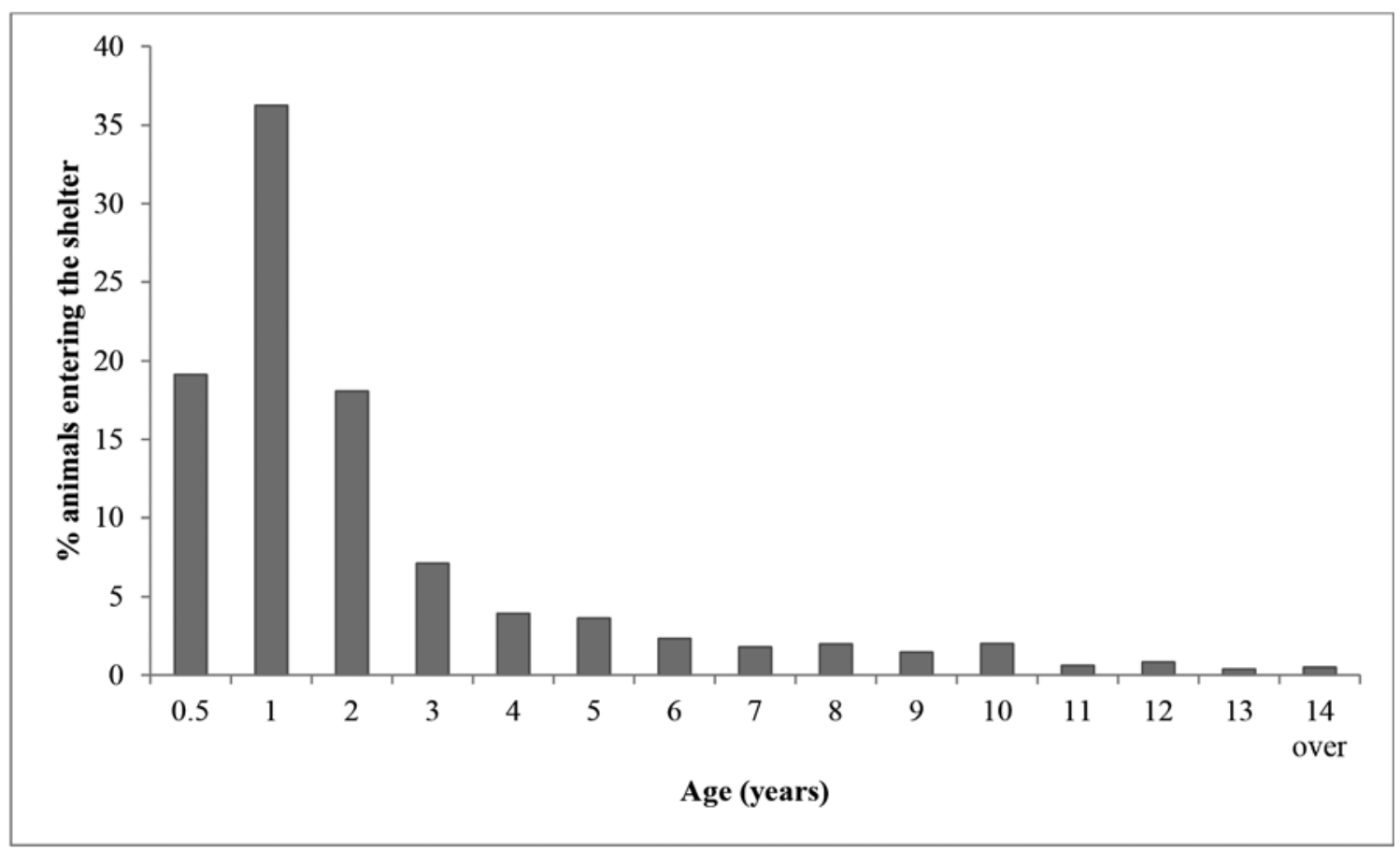

Figure 2. Age of animals entering the PS - Percentage of animals per age, entering the public shelter during the study period (2002-2013)

\section{Age}

Age was estimated by the veterinarians on the basis of the animals' dentition and general status (e.g. reproductive status) (12). The age range of the dogs entering the PS was variable, including puppies of few days old to dogs over 18 years old (mean 2.3; median 1.04; $\mathrm{Q}_{1}=0.7 ; \mathrm{Q}_{3}=2.6$ years-old). It was not possible to retrieve the data about the age of the dogs in the years 2000-2001, so age data refer to the period 2002-2013. As showed in Fig. 2, the age distribution is skewed to the left, with a peak at around one year-old (38\% of total animals entering the shelter).

The linear regression analysis highlighted a significant decrease in the average age of the dogs entering the shelter across the years $(b=-0.11$, $\mathrm{p}>0.0001$; Fig. 3).

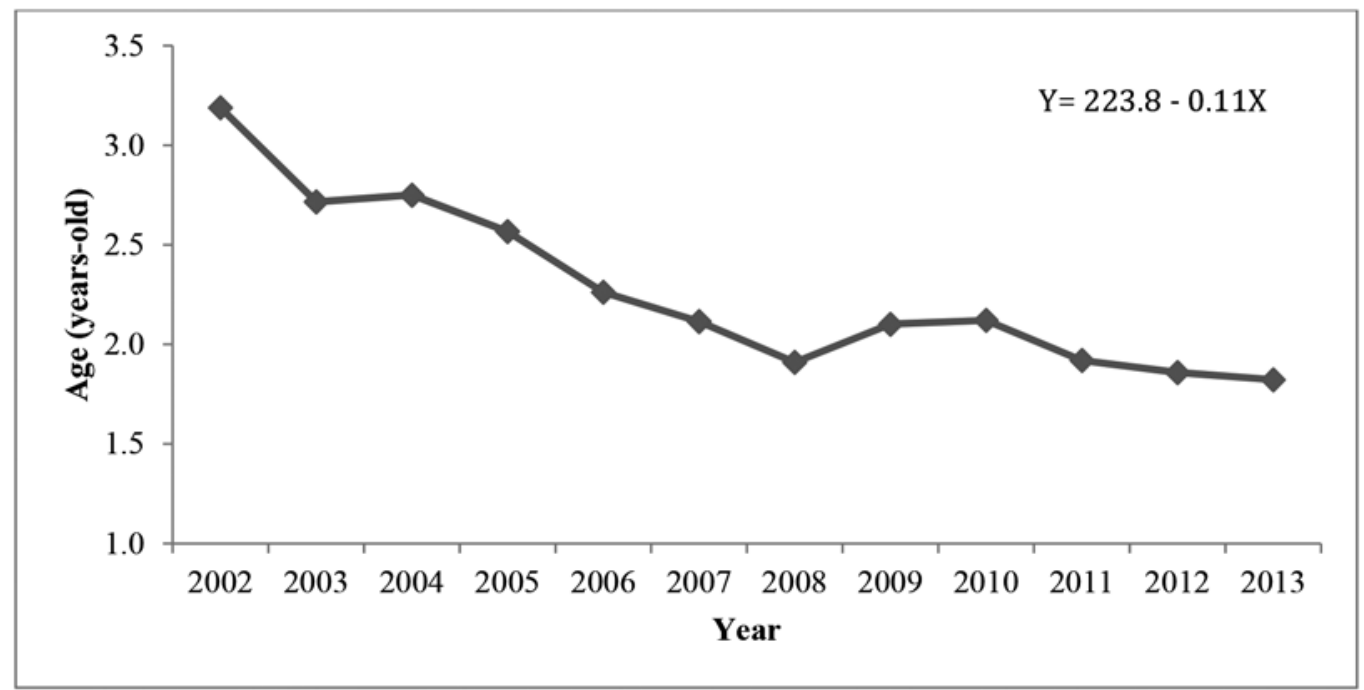

Figure 3. Average age of dogs entering the PS - Average age of dogs entering the public shelter each year, during the period of study (2002-2013) 
Free-roaming dogs control activities in one Italian province

Type of dogs entering the shelter and geographical origin

During the study period, 879 puppies $(12.8 \%$ of the total population), usually arriving in litters, entered the PS. However, most of the dogs captured from the territory were healthy adult FRDs (67.3\%; disease (e.g. gastro-enteric or respiratory disorders, mange, alopecia); and 1\% $(n=63)$ included abused animals, or dogs reported to predate livestock or other small animals. The majority of FRDs entering the PS were stray-unowned dogs (91\%), the remaining $9 \%(n=667)$ were owned dogs that

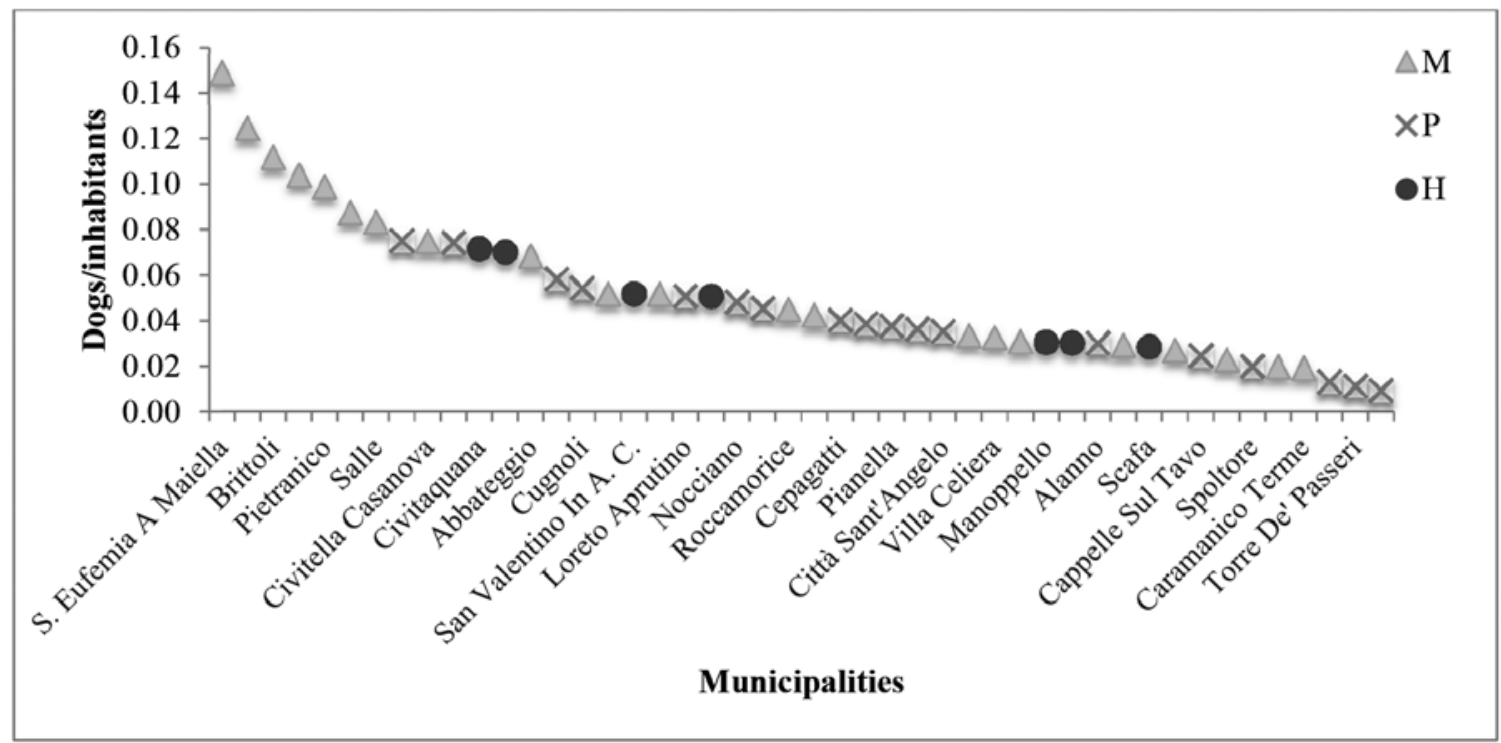

Figure 4. Geographical distribution of FRDs FRDs/inhabitant ratio per municipality associated to the type of territory $(\mathrm{M}=$ mountain; $\mathrm{P}=$ plain/costal; $\mathrm{H}=$ hill $)$, municipalities are ordered according to the FRDs/inhabitant ratio

average year entrance $=359.3$, median $=347.5$ dogs). The remaining fifth of the population was represented by $6.7 \%(n=463)$ of dangerous dogs, that either showed aggressive behaviours or had attacked people; 7.1\% $(\mathrm{n}=487)$ of injured animals (e.g. car accident); 5.2\% $(n=356)$ were found with a escaped or that were left free to roam unsupervised on the territory.

A significant positive correlation emerged between the number of captured dogs in each municipality and the human population $(\mathrm{R}=0.87$, $\mathrm{p}<0.0001)$. The 10 municipalities where most of

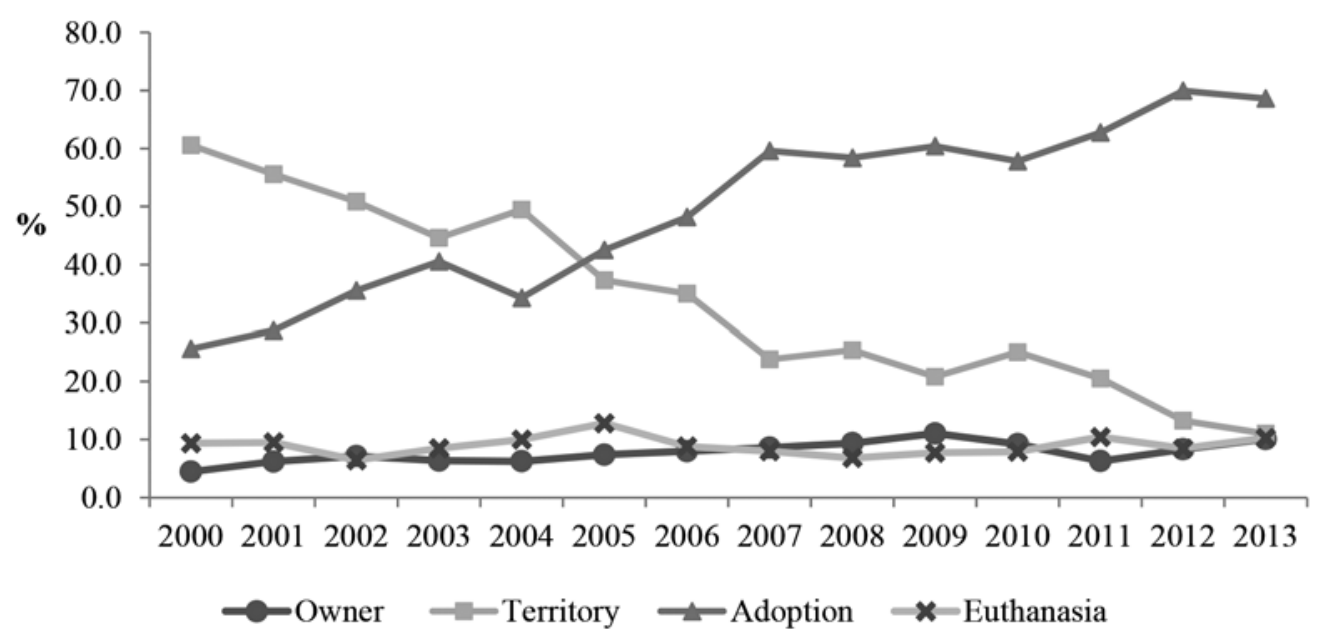

Figure 5. Destination of dogs after sheltering - Destination of dogs per year (i.e. return to the owner, return to the territory under TNR program, admission to an adoption program and euthanasia) 
the dogs were collected (64\% of all dogs) were the 10 municipalities with more inhabitants, also these were predominantly plain or coastal areas. When looking at the FRDs/inhabitants ratio instead, the 10 municipalities with the highest ratio were in the mountains (Fig. 4) although no significant difference emerged comparing the different types of territories among them $(\mathrm{H}=2.9, \mathrm{p}=0.23)$.

\section{Destination of dogs after sheltering}

After veterinary check-up, dogs could have different destinies. In the current study, $7.9 \%$ owned dogs returned to their owners, $50.8 \%$ unowned dogs were adopted or housed in rescue shelter for adoption, $32.3 \%$ were released on the territory as 'community dogs', and $8.9 \%$ of the total either died or were euthanized for reasons in compliance with the national law. The remaining 9 dogs $(0.1 \%)$ escaped from the PS. While a low percentage of dogs were returned to owners or euthanized, with rather constant numbers across the years, a clear increase in the number of animals destined for adoption can be seen with an opposite reduction in the number of dogs released on the territory (Fig. 5). Comparing these two groups (adoptions and territory) using a chi-square test revealed that before 2006 the number of animals destined for adoption was significantly below that expected by chance, while after 2006, it was significantly higher than would be expected by chance $\left(\chi^{2}=762.9 ; \mathrm{p}<0.0001\right)$.

\section{Bitelattack events}

A total of 463 dogs entered the PS of Pescara due to being involved in aggressive attacks or bite events. Of these, 65 (14\%) were owned dogs, whilst the remaining 398 were strays. The association between aggressive events and ownership was found to be significant $\left(\chi^{2}=15.3 ; \mathrm{p}<0.0001\right)$. In particular, the observed frequencies of aggressive owned dogs were significantly higher than the expected frequencies for this group.

Looking at breed types, $59.8 \%$ were mongrels (not ascribed to any specific breed) $7.6 \%$ were Abruzzi sheepdog cross-breeds, 5.2\% were Abruzzi sheepdog (pure breed), 5.2\% German shepherd dog cross breed, 5\% Pit Bull type, 3.9 and 3.7\% were German shepherd dog and Rottweiler respectively. Other breeds were represented by around $1 \%$ or below. After an accurate anamnesis and behavioural consultations most dogs were reintroduced on the territory, given up for adoption or returned to their owner $(\mathrm{n}=350)$. The remaining dogs $(21 \%)$ were declared dangerous and euthanized in accordance with law prescriptions.

\section{Sterilisation}

Sterilisation events were not reported in the record forms of the PS before 2002. During the remaining years, Pescara PS veterinarians performed 4,580 sterilisations, $85.6 \%$ on females. Among dogs entering in the PS, 289 were already neutered and among these, only 28 were owned out of a total of 667 (4.2\%) owned dogs. The average number of sterilisations per year between 2002 and 2013 was 381.7 (median 382; $\mathrm{Q}_{1}=360.3 ; \mathrm{Q}_{3}=407.5$ ).

Looking only at owned dogs, a highly significant association emerged between sex and neutering status $\left(\chi^{2}=21.7 ; p<0.0001\right)$. A significantly higher proportion of neutered female (85.7\%), compared to neutered male dogs (14.3\%), entered the shelter. On average, $350 \pm 29.4($ mean \pm SD) entire stray females and $17 \pm 7.1$ (mean $\pm \mathrm{SD})$ entire owned females dogs entered the PS each year. A significant difference also emerged when comparing the age of sterilised animals entering the PS, these being older than non-sterilised dogs (sterilised: mean $=5.9$ y.o.; nonsterilised: mean $=2.0 ; \mathrm{p}<0.0001$ )

\section{Identification}

A total of 515 FRDs captured from the territory were "community dogs" (under the TNR programme), therefore had an identification code (i.e. microchip). No free-roaming dog that had already been identified entered the PS in 2000 and only two did so in 2001. Between 2002 and 2013 a mean of $42.8 \pm 8.3 \mathrm{SD}$ already identified dogs per year entered the PS ( $8.9 \%$ of the average yearly entrance rate of unowned FRD entering the shelter), of which $42.5 \%$ were injured, ill or involved in attacks or bite events. According to their status, $28.3 \%$ dogs were returned to their territory, $19.2 \%$ died or were euthanized and $52.6 \%$ were adopted or committed to a rescue shelter for adoption. Among owned dogs $(\mathrm{n}=667), 61.8 \%$ had a transponder. The remaining $38.2 \%$ of owned dogs, which did not have a transponder, were not in compliance with the law. A chi-square test highlighted a significant association between the types of FRD (owned or stray) with the presence/absence of an identification code $\left(\chi^{2}=1605.8 ; p<0.0001\right)$. In particular, it emerged that observed frequencies of identified owned dogs were significantly higher than expected frequencies. PS veterinarians inoculated 5904 transponders to FRDs during 14 years.

\section{DISCUSSION}

\section{Demographic data}

Estimating the FRD population size and understanding its source is recognised to be the 
Free-roaming dogs control activities in one Italian province

first step needed to gain a picture of the baseline situation to plan targeted and effective actions, and to understand the amount of resources required to tackle this problem $(8,9,13)$.

It is reported that a $70 \%$ sterilisation rate is necessary to block dog population growth (14). Unfortunately, no reliable estimates of the FRD population in the province of Pescara is available at the moment, but since all dogs reported to the LVHU are captured and sterilised, it can be supposed that almost all FRD on the streets are eventually caught. TNR programmes in place for many years, as in this case study, should lead to a reduction of the reproduction rate and consequently to a progressive aging of the stray population. The present results highlight a high entrance rate of sub-adult animals (around 1 y.o., Fig. 2) and a rejuvenation of the population across the years (Fig. 3). Thus, the FRDs captured on the territory are new dogs, either born in the street or derived from abandoned and unwanted litters. This, together with the constantly high entrance rates at the PS (Fig. 1) are important symptoms of a failure in the dog population management system, which appears not to be targeting the source of new FRDs. It is important to consider the costs that a high capture and sterilisation activity entails for LVHU: sterilisation $70 € /$ dog plus capture, medical and maintenance costs (around $200 € / \mathrm{dog}$ ).

Although the more densely populated areas were those were the higher number of dogs were caught, on average a higher FRD-to-inhabitants ratio was found in mountain areas, being mostly rural or semi-rural (Fig. 4). The distribution of FRDs in the different geographical areas (plain, hill and mountain), however, did not differ statistically. As it also emerged in other dog surveys (15), in rural areas owners leave the dog free to roam, probably due to the higher tolerance by the community. In Abruzzi mountain areas pastoralism is common; farm stockperson often leave their dogs, mainly not sterilised, free to roam. Moreover, herders may abandon herding dogs that are not good for working thus contributing to the free roaming population of shepherd breed dogs (16). This behaviour could explain the higher prevalence of German Shepherds and Abruzzi Sheepdogs, both pure breed and their crosses, entering the PS (Table 1). Awareness and free microchipping campaigns targeting citizens may not reach farmers that rarely walk their working dogs to town. Targeted actions, such as door-todoor campaigns in rural areas and incentivising the sterilisation of non-working animals, would help in enforcing the law on identification and registration. This strategy, applied to the present and similar scenarios, could substantially reduce one of the sources of FRDs.
A certain ecological niche attracts animals according to the resource availability. Each niche has a carrying capacity therefore limiting the entrance of new individuals when resources are already taken. Reintroducing neutered dogs on the territory contributes to filling certain niches and is therefore one of the strategies applied to control FRD populations. The LVHU strategy has changed over the years, decreasing the number of dogs released on the territory as community dogs and increasing the number of animals destined for adoption (either direct or through rescue shelters; Fig. 5). Nevertheless, whichever was the primary DPM (dog population management) strategy used (i.e. TNR or sheltering), the average number of dogs entering the PS did not vary accordingly, suggesting once more that targeting only the 'symptom' of a problem and not the source has no effect in reducing the population size.

\section{Public health and animal welfare}

Dog bites to people are a serious issue for public safety, involving a high number of citizens every year in many countries all over the world, including Europe $(17,18)$. A total of 463 dogs entered the PS of Pescara because of involvement in aggressive attacks or bite events during the 14 years analysed here. Although observed frequencies of aggression events by owned dogs were higher than expected by chance alone, unowned animals represented the higher proportion of aggressive dogs entering the shelter. This result is in line with previous work carried out in Belgrade by Vučinić et al. (19) which also found that stray dogs caused a significantly higher number of bites to humans than owned dogs, although another study carried out in Italy show the opposite trend (20). Nevertheless, cases of attacks from dogs whose owner is unknown are known to be over-reported as compared to attack events from owned dogs. This may be due to people being more concerned about strays as carriers of diseases or conversely, because only serious bites are likely to be reported by victims of a family dog $(17,21)$. Also, previous works have highlighted how the reduction of the number of domestic animals roaming in the community could considerably help in preventing most bite injuries $(19,22)$.

Over one third of the population entering PS included injured, sick or abused animals, abandoned litters or biting animals. This data confirms that free roaming conditions in urban environments entail a range of risks to the dogs, potentially compromising their health and welfare, as well as being a potential threat for public safety as has also been reported elsewhere (3). A rather constant percentage of the caught animals were 'community dogs' (i.e. strays 
with an identification code), being recaptured every year. The re-catching of these animals implies costs as well, and this should be considered when deciding whether to implement TNR as a dog population management action.

\section{Responsible ownership}

Dog overpopulation can be a consequence of human behaviours, identified as deficiencies in pet maintenance and pet sterilisation $(23,24)$. Responsible ownership is a key factor in the control of FRD populations. In our study, 667 owned dogs were collected while roaming in the streets without supervision. This demonstrates irresponsible behaviour by dog owners in the province of Pescara. It was reported that dogs kept outside the house are less likely to be neutered, therefore increasing the probability of producing unwanted litters $(24,25)$.

Results from the PS show that a very low percentage of owned dogs caught from the street were sterilised (4.2\%), especially male dogs. Slater et al. (26) found similar results in Teramo, another province of the Abruzzi region, implying that cultural norms may underlie this phenomenon, as it has also been referred to in other papers (27, 28). In addition to owned dogs, just fewer than 400 entire female stray dogs were captured every year. These numbers are alarming when taking into account the number of litters and pups per litter that they could potentially generate if not neutered in time, thus the increase could be exponential. In accordance with other authors, we agree that methods to reduce the number of dogs that require rescue care should include increasing peoples' awareness of responsible ownership and also the provision of educational activities in schools. A significantly higher number of entire fertile animals were young dogs (i.e. around 2 y.o.), compared to sterilised dogs entering the shelter that were older animals. An increase in neutering rates, preferably at early stages of the dogs' life, may be necessary to reduce the risk of unwanted litters (29-31). This is also in line with OIE recommendations to promote responsible dog ownership, as it can significantly reduce the number of stray dogs. Also, due to dog ecology being linked to human activity effective control of dog populations has to be accompanied by changes in human behaviour (8). Høgåsen et al. (7) demonstrated through a deterministic model that the nuisance and costs associated with FRD population management can be effectively reduced by acting on dog ownership, decreasing the proportion of free roaming owned dogs and of abandonments, rather than by increasing kennel capacity. This model would allow significant savings, including reducing neutering costs at PS.
Since 2003, the Italian national law requires compulsory electronic dog identification and registration in the Regional Canine Registry (RCR) (32). An efficient traceability system plays a key role in dog population size and composition estimation. It also provides a tool to evaluate and monitor animal health, helping in disease outbreak management and surveillance (including zoonosis), vaccination programmes and welfare monitoring (33). However, the accuracy of the RCR also relies on the owners' diligence in registering and removing dogs after death, which has often proven to be lacking (34). For example, in a town of the Abruzzi region (Teramo), Slater and colleagues (26) found that $72 \%$ of the owners were aware about the RDR, but only half of them correctly registered their dogs. Voslárová and Passantino (6) highlighted that the province of Pescara was one of the most successful areas concerning dog identification compared to other Italian provinces. Despite this, in the present study, one third of caught owned dogs were not identified. Although a general yearly increase in the overall proportion of identified owned dogs could be discerned, there is still a good margin for improvement. A recent telephone interview study on dog ownership in the Pescara province confirms this data: $25.4 \%$ of owners did not identify their pet dog, although of these, only $3 \%$ admitted to being aware of the existence of the RDR (35). This data stresses once more the lack of awareness of the importance of an efficient traceability system for pet animals, and the need to increase citizens' knowledge on this topic.

\section{CONCLUSION}

Stray dog overpopulation is a serious public concern in several countries and difficulties in coping with FRDs are often consequences of limited eco-epidemiological data, poor planning, weak multidisciplinary and inter-sectorial collaboration and also a lack of resources (6). The condition of straying itself also entails risks for both dog health and welfare. Hence, actions targeted at preventing the causes that lead to the animals abandonment, such as overpopulation and behavioural problems, should be implemented (36). There is a need to find solutions that are economically sustainable, whilst bearing in mind the severe restriction in state-funding available regarding FRDs. The data presented in this paper adds to our understanding of dog population trends in the Pescara area. This may provide a basis for making policy decisions about effective methods to control overpopulation. The implemented neutering plan alone, targeting 
Free-roaming dogs control activities in one Italian province

FRDs, appears to be insufficient in controlling the local dog population. Veterinary services involved in DPM should consider these aspects of their local contexts when setting strategies to control FRD populations in their country.

\section{ACKNOWLEDGMENTS}

A special thanks to Dr. Fabrizio De Massis for his precious suggestions that helped improving this work and to Dr. Mary Friel for language revision.

\section{REFERENCES}

1. Slater, M. R. (2001). The role of veterinary epidemiology in the study of free-roaming dogs and cats. Preventive veterinary medicine 48(4): 273-286 http://dx.doi.org/10.1016/S0167-5877(00)00201-4

2. Kato, M., Yamamoto, H., Inukai, Y., Kira, S. (2003). Survey of the stray dog population and the health education program on the prevention of dog bites and dog-acquired infections: A comparative study in Nepal and Okayama prefecture, Japan. Acta Medica Okayama 57(5): 261-266. PMid:14679405

3. Vučinić, M., Đorđević, V., Radisavljević, K., Atanasijević, N., Nedeljković-Trailović, J. (2011). Feeding behavior of stray dogs in a municipal shelter. Acta veterinaria 61(1): 99-105. http://dx.doi.org/10.2298/AVB1101099V

4. Dalla Villa, P., Matthews, L. B., Alessandrini, B., Messori, S., Migliorati, G. (2014). Drivers for animal welfare policies in Europe. Revue Scientifique Et Technique-Office International Des Epizooties 33(1):,39-46.

5. Dalla Villa, P., Kahn, S., Stuardo, L., Iannetti, L., Di Nardo, A., Serpell, J. A. (2010). Free-roaming dog control among OIE-member countries. Preventive veterinary medicine $97(1): 58-63$

http://dx.doi.org/10.1016/j.prevetmed.2010.07.001 PMid:20709415

6. Voslářvá, E., Passantino, A. (2012). Stray dog and cat laws and enforcement in Czech Republic and in Italy. Annali dell'Istituto superiore di sanita 48(1): 97-104.

7. Hogasen, H. R., Er, C., Di Nardo, A., Dalla Villa, P. (2013). Free-roaming dog populations: a cost-benefit model for different management options, applied to Abruzzo, Italy. Preventive veterinary medicine 112(3-4): 401-413.

http://dx.doi.org/10.1016/j.prevetmed.2013.07.010 PMid:23973012

8. OIE (2014). 1st OIE regional workshop on stray dog population management for Balkan countries. Bucharest, RO, 17-19 June
9. OIE (2014). Terrestrial Animal Health Code. $23^{\text {rd }}$ ed. Paris

10. Italian law (1991). Legge n.281 of 4 Agosto 1991. In materia di animali d'affezione e prevenzione al randagismo. Gazzetta Ufficiale, n. 203, 30 agosto 1991

11. Diesel, G., Pfeiffer, D. U., Brodbelt, D. (2008). Factors affecting the success of rehoming dogs in the UK during 2005. Preventive Veterinary Medicine 84(3): $228-241$ http://dx.doi.org/10.1016/j.prevetmed.2007.12.004 PMid: 18243374

12. Fraser, Clarence M. (1986). The Merck veterinary manual. No. Ed. 6. Merck \& Co.

13. FAO (2014). Dog population management. Report of the FAO/WSPA/IZSAM expert meeting - Banna, Italy - 14-19 March 2011. Animal Production and Health Report. No. 6. Rome, Italy

14. Jackman, J., Rowan, A. N. (2007). Free-roaming dogs in developing countries: The benefits of capture, neuter, and return programs. Animal studies repository. In D.J. Salem \& A.N. Rowan (Eds.), The state of the animals 2007 (pp. 55-78). Washington, DC: Humane Society Press

15. Brickner, I. (2002). The impact of domestic dogs (Canis familiaris) on wildlife welfare and conservation: a literature review

16. Namgail, T., Fox, J. L., Bhatnagar, Y. V. (2007). Carnivore-caused livestock mortality in TransHimalaya. Environmental Management 39(4): 490-496.

http://dx.doi.org/10.1007/s00267-005-0178-2 PMid:17318699

17. Butcher, R. L., De Keuster, T. (2013). Dog-associated problems affecting public health and community wellbeing. Dogs, Zoonoses and Public Health, $2^{\text {nd }}$ Ed., 24-42. http://dx.doi.org/10.1079/9781845938352.0024

18. Santoro, V., Smaldone, G., Lozito, P., Smaldone, M., Introna, F. (2011). A forensic approach to fatal dog attacks. A case study and review of the literature. Forensic Science International 206(1-3): E37-E42. http://dx.doi.org/10.1016/j.forsciint.2010.07.026 PMid:20719439

19. Vučinić, M., Dordevic, M., Brana, R.-D., Ljiljana, J., Mirilovic M. (2008). Bites to humans caused by stray and owned dogs in Belgrade. Acta VeterinariaBeograd 58(5-6): 563-571. http://dx.doi.org/10.2298/AVB0806563V

20. Fedele, V., Gnaccarini, M., Laurenti, P., Marino, M., Meia, B. (2008). Monitoraggio delle morsicature nel pinerolese negli anni 1998 - 2008. Argomenti 4, 53-59. 
21. Overall, K. L., Love, M. (2001). Dog bites to humans - demography, epidemiology, injury, and risk. Journal of the American Veterinary Medical Association 218(12): 1923-1934

http://dx.doi.org/10.2460/javma.2001.218.1923

PMid:11417736

22. Sinclair, C. L., Zhou, C. (1995). Descriptive epidemiology of animal bites in Indiana, 1990-92 a rationale for intervention. Public Health Reports 110(1): 64-67. PMid:7838946 PMCid:PMC1382076

23. Fournier A. K., Geller E. S. (2005). Behavior analysis of companion-animal overpopulation: A conceptualization of the problem and suggestions for intervention. Behav. Soc. 13, 51-68. http://dx.doi.org/10.5210/bsi.v13i1.35

24. Fielding, W. J. (2010). Dog breeding in New Providence, The Bahamas, and its potential impact on the roaming dog population I: planned and accidental. Journal of applied animal welfare science: JAAWS. 13(3): 250-260.

25. Slater, M. R., Di Nardo, A., Pediconi, O., Dalla Villa, P., Candeloro, L., Alessandrini, B., Del Papa, S. (2008). Free-roaming dogs and cats in central Italy: Public perceptions of the problem. Preventive veterinary medicine 84(1): 27-47

http://dx.doi.org/10.1016/j.prevetmed.2007.10.002 PMid:18055046

26. Slater, M. R., Di Nardo, A., Pediconi, O., Villa, P. D., Candeloro, L., Alessandrini, B., Del Papa, S. (2008). Cat and dog ownership and management patterns in central Italy. Preventive veterinary medicine 85(3-4): 267-294.

http://dx.doi.org/10.1016/j.prevetmed.2008.02.001 PMid:18374434

27. Levy, J. K., Crawford, C., Appel, L. D., Clifford, E. L. (2008). Comparison of intratesticular injection of zinc gluconate versus surgical castration to sterilize male dogs. American journal of veterinary research 69(1): 140-143.

http://dx.doi.org/10.2460/ajvr.69.1.140 PMid:18167099

28. McKenzie, B. (2010). Evaluating the benefits and risks of neutering dogs and cats. CAB Reviews: Perspectives in agriculture, veterinary science, nutrition and natural resources 5(045). http://dx.doi.org/10.1079/PAVSNNR20105045

29. Clark, C. C. A., Gruffydd-Jones, T., Murray, J. K. (2012). Number of cats and dogs in UK welfare organisations. Veterinary Record 170(19): 493. http://dx.doi.org/10.1136/vr.100524 PMid:22589036
30. Di Nardo, A., Candeloro, L., Budke, C. M., Slater, M. R. (2007). Modeling the effect of sterilization rate on owned dog population size in central Italy. Preventive veterinary medicine 82(3-4): 308-313. http://dx.doi.org/10.1016/j.prevetmed.2007.06.007 PMid: 17692414

31. Voith, V. L. (2009). The impact of companion animal problems on society and the role of veterinarians. Vet Clin N Am-Small., 39(2): 327.

32. Italian law (2003). Accordo del 6 Febbraio 2003 tra il Ministro della salute, le regioni e le province autonome di Trento e di Bolzano in materia di benessere degli animali da compagnia e pet-therapy. Gazzetta Ufficiale, n. 51, 03/03/2003

33. Dalla Villa, P., Messori, S., Possenti, L., Barnard, S., Cianella, M., Di Francesco, C. (2013). Pet population management and public health: a web service based tool for the improvement of dog traceability. Preventive veterinary medicine 109(3-4): 349-353 http://dx.doi.org/10.1016/j.prevetmed.2012.10.016 PMid:23182028

34. Caminiti, A., Sala, M., Panetta, V., Battisti, S., Meoli, R., Rombola, P., Spallucci, V., Eleni, C., Scaramozzino, P. (2014). Completeness of the dog registry and estimation of the dog population size in a densely populated area of Rome. Preventive veterinary medicine 113(1): 146-151. http://dx.doi.org/10.1016/j.prevetmed.2013.10.003 PMid:24188820

35. Magnani, D., Barnard, S., Messori, S., Di Bonaventura, I., Giovannini, A., Dalla Villa, P., Ferri, N. (2015). Investigation on responsible ownership in two different urban context. Proceedings $2^{\text {nd }}$ International conference on dog population management; Istanbul, Turkey, 3-5 March (p.63)

36. Verga, M., Michelazzi, M. (2009). Companion animal welfare and possible implications on the human-pet relationship. Ital J Anim Sci., 8(1s): 231-240. http://dx.doi.org/10.4081/ijas.2009.s1.231

Please cite this article as: Barnard S., Chincarini M.,Tommaso LD., Giulio FD., Messori S., Ferri N. Free-roaming dogs control activities in one Italian province (2000-2013): Is the implemented approach effective? Mac Vet Rev 2015; 38 (2): 149-158. http://dx.doi.org/10.14432/j.macvetrev.2015.04.041 